\title{
OS DESDOBRAMENTOS SOCIOAMBIENTAIS DA TERRITORIALIZAÇÃO DO CAPITAL NO CERRADO BRASILEIRO ${ }^{1}$
}

Leandro Reginaldo Maximino Lelis ${ }^{2}$

Francisco José Avelino Junior ${ }^{3}$

RESUMO

A partir da década de 1960, o campo brasileiro passou por alterações estruturais significativas, sobretudo, em função da territorialização do capital. Essa territorialização contou com forte apoio e incentivo do Governo Federal e tinha como objetivo principal proporcionar a modernização da agricultura. A referida modernização seria realizada com o intuito de aumentar a produção e a produtividade agrícola a fim de promover a internacionalização da economia brasileira. No Cerrado, esse processo de territorialização do capital ocorreu a partir da década de 1970 e provocou alterações significativas do ponto de vista econômico, social e ambiental. Nesse contexto, o presente trabalho tem como objetivo analisar o processo de territorialização do capital que ocorreu no Cerrado, com ênfase em seus desdobramentos socioambientais. A partir da leitura do material bibliográfico selecionado, pudemos notar que a mesma territorialização do capital que proporcionou a modernização da agricultura e, por consequência, o aumento da produção e da produtividade agrícola, também foi responsável por expulsar milhares de famílias do campo, desarticular comunidades rurais tradicionais, aumentar a concentração fundiária e de renda, além de gerar desdobramentos ambientais negativos, como o desmatamento da vegetação nativa, a redução da biodiversidade e a poluição do solo, dos recursos hídricos e da vegetação em função do uso demasiado de agrotóxicos.

PALAVRAS-CHAVE: Territorialização. Capital. Cerrado.

\section{THE SOCIAL AND ENVIRONMENTAL DEVELOPMENTS OF TERRITORIALIZATION CAPITAL IN THE BRAZILIAN CERRADO}

\footnotetext{
${ }^{1}$ Pesquisa de mestrado em desenvolvimento financiada pela Fundect/Capes.

${ }^{2}$ Mestrando no Programa de Pós-Graduação em Geografia da Universidade Federal de Mato Grosso do Sul, campus de Três Lagoas. Bolsista Fundect/Capes. E-mail: sukko51@hotmail.com.

${ }_{3}$ Docente do Programa de Pós-Graduação em Geografia da Universidade Federal de Mato Grosso do Sul, campus de Três Lagoas. E-mail: chinaufms@hotmail.com.
} 


\begin{abstract}
From the 1960s, the Brazilian countryside passed for significant structural alterations, mainly, due to the territorialization of capital. This territorialization counted with strong support and encouragement of the Federal Government and its main objective was to provide the modernization of agriculture. The said modernization would be performed aiming to increase production and agricultural productivity in order to promote the internationalization of the Brazilian economy. In the Cerrado, this process of territorialization of capital occurred as from the 1970s and sparked significant alterations in economic, social and environmental perspective. In this context, this paper aims to analyze the process of territorialization of capital that occurred in Cerrado, with emphasis on its social and environmental developments. From reading the bibliographic material selected, we noted that the same territorialization of capital that provided the modernization of agriculture and, consequently, increased production and agricultural productivity, was also responsible for expelling thousands of countryside families, disrupt traditional rural communities, increase landholding and income concentration, and generate negative environmental developments such as deforestation of native vegetation, reduced biodiversity and soil pollution, water resources and vegetation due to the too much usage of agrotoxics.
\end{abstract}

KEYWORDS: Territorialization. Capital. Cerrado.

\title{
LOS DESARROLLOS SOCIOAMBIENTALES DE TERRITORIALIZACIÓN DEL CAPITAL EM EL CERRADO BRASILEÑO
}

\section{RESUMEN}

Partir de la década de 1960, el campo brasileño pasó por modificaciones estructurales significativos, principalmente, debido a la territorialización del capital. Esta territorialización tuvo un fuerte apoyo y aliento del Gobierno Federal y su objetivo principal era proporcionar a modernización de la agricultura. Esta modernización se realizará con el fin de aumentar la producción y la productividad agrícola para promover la internacionalización de la economía brasileña. En el Cerrado, este proceso de territorialización del capital ocurrió a partir de la década de 1970 y provocó cambios significativos en la punto de vista económico, social y ambiental. En este contexto, el presente trabajo tiene como objetivo analizar el proceso de territorialización del capital que ocurrió en Cerrado, con énfasis en sus consecuencias sociales y ambientales. De la lectura del material bibliográfico seleccionado, observamos que el mismo territorialización del capital, que provocó la modernización de la agricultura y, en consecuencia, el aumento de la producción y la productividad agrícola, también fue responsable de la expulsión de miles de familias rurales, perturbar a las comunidades rurales tradicionales, el aumento de la concentración de tierras e ingresos, además de generar consecuencias ambientales negativas, como la deforestación de la vegetación nativa, reduciendo la biodiversidad y la contaminación del suelo, los recursos hídricos y la vegetación debido al uso excesivo de pesticidas.

PALABRAS CLAVE: Territorialización. El capital. Cerrado. 


\section{INTRODUÇÃO}

Buscando alcançar o objetivo de promover a internacionalização da economia, o Estado brasileiro foi fundamental para possibilitar as condições necessárias para a territorialização do capital no campo. Isso porque, a partir da década de 1950, a agricultura passou a ser vista como uma forma de viabilizar essa internacionalização. No entanto, para que isso ocorre seria necessário aumentar a produção e a produtividade agrícola. O caminho escolhido para lograr êxito em tal intento foi a modernização das atividades agrícolas. Após grandes investimentos financeiros esse processo de modernização começou a se concretizar a partir da década de 1960. A partir desse período, o campo brasileiro passou por alterações estruturais significativas em decorrência da territorialização do capital.

O Cerrado foi incorporado a essa lógica capitalista a partir da década de 1970. Antes da territorialização do capital agir com o intuito de proporcionar a modernização da agricultura, o Cerrado era tido como sinônimo de pobreza. Tal situação ocorria, principalmente, em função da invisibilidade do referido bioma perante aos interesses do capital. A partir da década de 1970 essa situação foi alterada. Contanto com o apoio do capital privado nacional e internacional, o Estado brasileiro realizou uma série de medidas e investimentos financeiros com o intuito de inserir o Cerrado brasileiro nas demandas da economia internacional.

Nesse contexto, o presente trabalho tem como objetivo analisar o processo de territorialização do capital que ocorreu no Cerrado a partir da década de 1970, com ênfase em seus desdobramentos socioambientais. Para a consecução do objetivo proposto, realizamos uma revisão bibliográfica acerca dos seguintes temas: territorialização do capital no campo; modernização da agricultura; e, expansão do agronegócio no Cerrado.

\section{DESENVOLVIMENTO}

\subsection{A territorialização do capital no campo brasileiro}


Em certo período da história, a agricultura era considerada como o setor tradicional da economia que prejudicava o desenvolvimento industrial no Brasil. Isso ocorria em função de sua incapacidade de fornecer a quantidade necessária de matéria-prima para as fábricas, bem como pelo pequeno poder de compra dos trabalhadores agrícolas, que impossibilitava que eles consumissem produtos industrializados (ANDRANDE, 1979).

Posteriormente, esse pensamento foi alterado e a agricultura passou a ser vista como uma forma de inserção do Brasil na economia internacional. Todavia, para que isso ocorresse, era necessário aumentar a produção e a produtividade agrícola. A estratégia escolhida pelo Estado brasileiro para alcançar esse objetivo foi a modernização das atividades agrícolas. Desse modo, a partir década de 1950, o Estado propagou a ideia de que a modernização da agricultura era necessária para o desenvolvimento econômico do país. No entanto, foi somente a partir da década de 1960 que a modernização da agricultura começou a se consolidar (ANDRADE, 1979).

Para Oliveira (1996), a dívida externa foi o principal motivo para que ocorresse o aumento da produção destinada ao mercado externo. Isso porque, para quitar suas dívidas o governo brasileiro tinha que exportar. Assim, o Brasil teve que ampliar a produção para conseguir continuar pagando suas dívidas, já que os preços das matérias-primas que o Brasil exportava naquele período estavam em baixa.

O Governo Federal exerceu papel fundamental para viabilizar a consolidação da modernização da agricultura no Brasil. Através dos órgãos governamentais foram repassados uma série de investimentos financeiros que possibilitaram essa modernização. A grande questão foi a desigualdade existente durante a destinação desses investimentos. Enquanto os grandes produtores rurais usufruíram de uma série de vantagens e facilidades, os pequenos produtores sofreram com a falta de apoio e incentivo governamental, ficando, dessa forma, marginalizados perante a essa série de investimentos estatais no campo brasileiro (ANDRADE, 1979). A respeito dos benefícios concedidos a agricultura praticada em grande escala, Andrade corrobora que

Procura-se montar todo um sistema que visa proteger e subvencionar a grande agricultura, estimulando-se o processo de mecanização agrícola, 
facilitando-se o crédito para formação de plantios e para a implantação e modernização de instalações, a assistência agronômica etc. em favor da agricultura de exportação (ANDRADE, 1979, p. 62).

Desta maneira, a expansão do modo de produção capitalista no campo brasileiro só foi possível graças ao apoio governamental. Este apoio se deu através de facilidades de financiamento às grandes propriedades, isenção de impostos, entre outros benefícios.

[...] um importante ponto a considerar é que a transformação capitalista da agricultura brasileira tem que estar referenciada à política do Estado que, sem sombra de dúvida, tem criado mecanismos que favorecem a capitalização da grande propriedade (GRAZIANO DA SILVA, 1982, p. 39).

Graziano da Silva (1982) também aponta que a presença marcante do Estado no setor agrícola foi um dos fatores responsáveis pelas contradições existentes no desenvolvimento do capitalismo no campo brasileiro.

Ressaltando o papel do Estado no setor agrícola, Martins (1975) afirma que a política econômica estatal regula o setor externo e o setor interno. Destarte, os produtos agrícolas destinados ao mercado externo e interno são regulados pelo Estado, "[...] seja porque deles depende substancialmente a receita cambial do país, empregada na industrialização, seja porque passaram a ter consumo expressivo ou preponderante no mercado interno" (MARTINS, 1975, p. 59).

Kudlavicz (2011) aponta que a expansão do agronegócio no Brasil só foi possível em função de um planejamento bem articulado entre o poder público e o privado. Nesse sentido, o referido autor ressalta a importância das instituições de pesquisa para a consolidação da modernização das atividades agropecuárias desenvolvidas no Brasil.

Analisando os fatos é possível dizer que há uma relação direta entre as instituições de pesquisa, de modo particular na década de 1970, e as ações que irão nortear a expansão do agronegócio brasileiro. Portanto, não há nada de natural neste processo de desenvolvimento capitalista no campo brasileiro, ao contrário, o que vemos é o planejamento cujo ponto de apoio é a articulação entre o capital, o Estado e as instituições de pesquisa e extensão rural (KUDLAVICZ, 2011, p. 56). 
Conforme Andrade (1979), os meios de comunicação também possuíram papel fundamental para a consolidação do processo de modernização da agricultura, já que eles foram utilizados para disseminar a ideia de que a modernização e o consequente aumento da produção e da produtividade agrícola beneficiariam a população. Seguindo esse princípio, os meios de comunicação difundiram a ideia que os danos sociais e ambientais seriam prejuízos necessários para que ocorresse o desenvolvimento e o progresso. Compartilhando desse ponto de vista, Almeida (2012) destaca que:

[...] o desenvolvimento econômico é um mito cuja funcionalidade é criar um imaginário coletivo centrado na ideia de que todos serão beneficiados pelo desenvolvimento do capital, situação que leva os povos a aceitar sacrifícios que incluem formas de dependência e de destruição do meio físico (ALMEIDA, 2012, p. 12).

Sobre a territorialização do capitalismo no campo, Matos e Pessoa (2009) afirmam que esse processo proporcionou muito mais desvantagens do que vantagens. Como vantagens os autores citam o aumento da produção e da produtividade agropecuária que ocorreram em função das inovações tecnológicas. Já do ponto de vista negativo, apontam que esse processo contribuiu para aumentar a concentração fundiária e de renda, além de aumentar as desigualdades regionais e expulsar milhares de famílias do campo.

As inovações tecnológicas que proporcionam o aumento da produção e da produtividade agropecuária também possuem grande responsabilidade na expulsão de milhares de famílias no campo. Tal situação ocorre porque o trabalho humano é cada vez mais substituído pelas máquinas. Além disso,

As inovações tecnológicas fazem com que, cada vez mais, a produção se torne menos dependente da natureza, pois as técnicas passam a subordinar a natureza a gosto do capital, re-produzindo artificialmente várias condições necessárias a produção agrícola (MATOS; PESSOA, 2009, p. 4).

A menor dependência em relação aos aspectos naturais faz com que o ciclo de produção agropecuário diminua cada vez mais, fato que é interessante para o capital, haja vista que a redução do tempo de produção implica em uma lucratividade maior. 
De acordo com Graziano da Silva (1982), o papel principal das inovações tecnológicas na agricultura é o de produzir instrumentos que aumentem a produtividade da terra e do trabalho, além de submeter o processo produtivo aos interesses do capital.

Para Graziano da Silva (1982), o que se vê no campo brasileiro é uma "modernização conservadora", haja vista que tal processo de modernização privilegia somente algumas culturas (principalmente as destinadas ao mercado externo) e regiões, bem como, somente alguns tipos de unidades produtivas (médias e grandes propriedades rurais). Assim, o processo de modernização do campo brasileiro nunca possuiu um caráter dinâmico e homogêneo, pelo contrário, essa modernização induzida implicou em "[...] pesados custos sociais e que só vinga pelo amparo do Estado" (GRAZIANO DA SILVA, 1982, p. 40).

Como pôde ser observado, a territorialização do capital no campo e a consequente modernização das atividades agrícolas provocaram alterações profundas na dinâmica social, econômica e ambiental do campo brasileiro. No Cerrado não foi diferente, como veremos no próximo subitem.

\subsection{A territorialização do capital no Cerrado}

Durante muito tempo, o Cerrado era tido como sinônimo de pobreza em decorrência, principalmente, de sua invisibilidade perante aos interesses do capital. Tal situação foi alterada, principalmente, a partir da década de 1970. Nesse período, o poder estatal com o apoio do capital privado nacional e internacional realizou uma série de investimentos e implantou um conjunto de medidas com o intuito de inserir referido bioma nas demandas da economia internacional.

\footnotetext{
Um conjunto de políticas públicas nacionais consorciadas com instituições do mundo desenvolvido, a partir do incremento de ciência, tecnologia e saber importados e por meio de subsídios e organização de logística pelo Estado brasileiro, foram tecidas como estratégias geopolíticas, ideológicas e econômicas para transformar o Bioma num território produtivo (CHAVEIRO; CALAÇA, 2012, p. 194).
}

Essa situação alterou a dinâmica econômica do Cerrado, já que o referido bioma deixou de ser uma área estagnada para se tornar uma área de prosperidade 
econômica. Dessa mesma forma a natureza foi modificada, pois passou de uma área preservada para uma área onde as espécies são destruídas. Além disso, também ocorreram mudanças no modo de vida dos povos cerradeiros principalmente daqueles que habitam o campo -, já que estes passaram a viver em função de uma nova lógica. Nesse sentido, Chaveiro e Calaça (2012) salientam que:

\footnotetext{
Por esse viés, a ação do capital sobre o Cerrado ou o que Calaça (2010) chama "territorialização do capital" impacta o mundo dos sujeitos que aqui viviam - e vivem - criando modos de desenraizá-los, alterando seus modos de vida, interferindo em seus valores e em sua cultura (CHAVEIRO; CALAÇA, 2012, p. 195).
}

A interferência da ação do capital no modo de vida daqueles que habitam o campo ocorre com maior intensidade, sobretudo, nas áreas onde a modernização agrícola se expande. Nessas áreas "[...] há transformação no modo de vida da população residente, pois são inseridos novos valores, os quais se aproximam dos valores urbanos" (MATOS; PESSOA, 2009, p.5). Tal situação contribui para que a dinâmica de comunidades rurais tradicionais seja alterada.

Porto Gonçalves (2004) aponta que o cerrado brasileiro e sua enorme diversidade biológica e cultural vêm se transformando numa área propicia para a expansão de grandes latifúndios produtivos. Essa expansão ocorre em função das inúmeras vantagens existentes - riqueza hídrica, topografia plana, entre outros fatores - nesse bioma. Ainda segundo Porto Gonçalves (2004), em 2004, estimavase que $70 \%$ da área das chapadas já estavam ocupadas pelo agronegócio.

De acordo com Canuto (2004), o Cerrado é o bioma do território brasileiro mais ameaçado pela expansão do agronegócio. O Cerrado também é qualificado como a savana mais rica do mundo no que diz respeito à biodiversidade. Entretanto, apenas $2 \%$ de seu território está protegido na forma de Unidades de Conservação, o que mostra a vulnerabilidade desse bioma perante o avanço do agronegócio. Além disso, o Cerrado possui uma riqueza hídrica enorme, já que nesse bioma nascem importantes rios brasileiros como: Araguaia, São Francisco, Paraná, Tocantins, entre outros. Sobre a expansão desenfreada do agronegócio no Cerrado brasileiro, Canuto (2004) exalta que: 
O agronegócio é devastador. Imensas áreas de florestas e do cerrado estão sendo ilegalmente desmatadas, secando nascentes e mananciais, sugados pelo ralo das monoculturas, pastos de capim, carvoarias, mineradoras e madeireiras. Os agrotóxicos, despejados por aviões e tratores, estão contaminando solos, águas, ar e as plantações camponesas, causando doenças e mortes (CANUTO, 2004, p. 10).

A nova lógica que passou a reger o Cerrado, baseada nas demandas da economia internacional, provocou uma mudança estrutural. O modelo tradicional e característico do Cerrado perdeu espaço, pois a partir da territorialização do capital é o modelo moderno, liderado pela monocultura e pela pecuária intensiva, que passa a ser o modelo a ser seguido no território cerradeiro. Segundo Chaveiro e Calaça (2012, p. 195): “a inserção do Cerrado na economia internacional, a um só tempo, substitui a economia de subsistência baseada no modelo fazenda e roça para o da monocultura de soja e pastagem". De acordo com Fidelis e Lima (2009):

O Cerrado sofreu uma grande intervenção da agricultura moderna, principalmente nos chapadões, onde retirou-se toda a vegetação e instalaram-se projetos de agronegócio com imensas monoculturas da soja, trigo, milho e outras (FIDELIS; LIMA, 2009, p. 8).

Além das alterações já mencionadas que ocorreram em função da territorialização do capital, também se pode afirmar que a modernização do campo contribui para que ocorram mudanças efetivas no território cerradeiro. Nesse sentido, Matos e Pessoa (2009, p. 8) apontam que "[...] a territorialização do capital nas atividades agrícolas nas áreas de Cerrado provocou, e ainda provoca um reordenamento territorial".

A respeito das alterações estruturais proporcionadas pela expansão da agricultura moderna no Cerrado, Matos e Pessoa (2009) salientam que as áreas que foram inseridas no processo de territorialização do capital têm passado por

[...] mudanças radicais em sua organização produtiva, social e ambiental. No setor produtivo, são inseridas novas culturas e novos métodos de produção agregado aos conteúdos das tecnologias. O social é atingido sob vários aspectos, mas especialmente, pela exclusão de muitos produtores rurais do processo produtivo e pelos desdobramentos ambientais que vão desde a destruição da fauna e flora até dos recursos hídricos (MATOS; PESSOA, 2009, p. 9). 
Sobre o processo de territorialização do capital no campo, Calaça $(2010$, p. 9) enfatiza que: "esse processo, que se convencionou denominar de modernização da agricultura, constitui-se de importantes transformações na base biotecnológica da agropecuária". Ainda segundo Calaça (2010), a territorialização do capital possibilitou a modernização das atividades desenvolvidas no campo, além do desenvolvimento de pesquisas que visavam superar as limitações ambientais do bioma Cerrado no que diz respeito à produtividade agrícola.

A respeito da importância da tecnologia para o desenvolvimento das atividades agrícolas no Cerrado, Fidelis e Lima (2009) afirmam que:

\begin{abstract}
A tecnologia nos diversos setores permitiu ao homem ocupar espaços que antes ele não podia ocupar, e assim foi com o Cerrado brasileiro, a ocupação dos solos ácidos, possibilitada pelo uso de fertilizantes e corretivos de solo propiciaram que as monoculturas de soja, milho, eucalipto e outras, de um modo geral, se instalassem nos Latossolos do Cerrado (FIDELIS; LIMA, 2009, p. 9).
\end{abstract}

Para Calaça (2010), o processo de modernização agrícola e a consequente incorporação da biotecnologia no campo foram responsáveis por alterar "[...] as práticas agrícolas, as relações sociais de produção, a interação com a natureza, modificando as práticas dos camponeses e dos agricultores tradicionais do Cerrado" (CALAÇA, 2010, p. 16). Além disso, Calaça (2010) também aponta que ao criar condições para a expansão da biotecnologia, o processo de territorialização do capital favorece a substituição da biodiversidade pela agrobiodiversidade. Tal substituição acarreta em um prejuízo ambiental enorme, já que a biodiversidade apresenta uma diversidade de plantas e animais superior ao dos agroecossistemas.

Baseado em dados da Organização das Nações Unidas para Alimentação e Agricultura (FAO), Porto Gonçalves (2004) aponta que nos últimos cinquenta anos, a produção de grãos aumentou três vezes enquanto que o uso de fertilizantes foi multiplicado quatorze vezes.

A expansão exponencial do uso de adubos e fertilizantes, herbicidas, pesticidas e fungicidas vem sendo há décadas objeto de intensas críticas de ambientalistas, de órgãos ligados à saúde e de sindicatos de trabalhadores sobretudo rurais (PORTO GONÇALVES, 2004, p. 225). 
O uso demasiado de agrotóxicos têm provocado inúmeros prejuízos ambientais. Dessa forma, os recursos hídricos, o solo, a vegetação e até os seres humanos são afetados pela utilização exacerbada dos defensivos agrícolas.

Kudlavicz (2011) salienta que o uso intensivo de agrotóxicos é consequência da expansão do modelo agrário-agrícola exportador baseado na monocultura. Ainda para o autor, esse uso intensivo pode causar danos irreparáveis para o meio ambiente, já que contribui para a simplificação dos ecossistemas e para a diminuição da biodiversidade.

Além dos danos ambientais ocasionados pela utilização demasiada de agrotóxicos, a expansão do agronegócio também favorece o desmatamento da vegetação nativa. Nesse sentido, Canuto (20004) enfatiza que:

O agronegócio provoca consequências desastrosas ao meio-ambiente. Carrega na sua esteira o mais surpreendente e rápido desmatamento de que se tem conhecimento na história brasileira. Este desmatamento atinge dois biomas em especial, o Cerrado e a Floresta Amazônica (CANUTO, 2004, p. 7-8).

Cabe ressaltar que o processo de territorialização do capital não ocorreu com a mesma intensidade em todas as porções do Cerrado, haja vista que algumas áreas acabaram atraindo mais a atenção do capital, enquanto outras ficaram às margens desse processo. A respeito das áreas que são ou não escolhidas para a territorialização do capital, Chaveiro e Calaça (2012) pontuam que:

\footnotetext{
Além da posição territorial, especialmente a aproximação com os centros de economia hegemônica como o Sul e o Sudeste do país, os contextos históricos de cada lugar, ou os espaços herdados, participam direta - e decisivamente - da escolha estratégica para a territorialização do capital (CHAVEIRO; CALAÇA, 2012, p. 195).
}

Desse modo, sabendo que a territorialização do capital não ocorreu da mesma maneira e com a mesma intensidade em todas as áreas do Cerrado, Chaveiro e Calaça (2012), afirmam que modelos de produção mais antigos coexistem com modelos modernos. Nesse contexto, os autores corroboram que: "[...] outros modelos de produção resistem, adaptam-se, convertem ou pactuam com o modelo moderno. Embora haja outros modelos, a hegemonia é da modernização do território" (CHAVEIRO; CALAÇA, 2012, p.197). 
Além da existência de outros modelos de produção, também se pode afirmar que outros modelos de relações sociais continuam existindo mesmo após a intensificação da ação do capital no campo. Nesse sentido, Lima (2012) afirma que:

No interior do processo de territorialização do capital há a criação, destruição e recriação do trabalho familiar camponês, pois o capitalismo não é capaz de conter apenas um modelo de relação social (LIMA, 2012, p. 142).

Chaveiro e Calaça (2012) apontam que nas últimas décadas, a expansão do capital no campo ocorreu em diversos estados brasileiros que possuem o bioma Cerrado - Goiás, Minas Gerais, Mato Grosso, Mato Grosso do Sul, dentre outros - e que essa expansão provoca conflitos "[...] entre a territorialização do capital em escala global e as territorialidades locais [...]" (CHAVEIRO, CALAÇA, 2012, p.197).

No campo, estes conflitos ocorrem "[...] entre os proprietários/capitalistas enquanto personificação do agronegócio na busca de terras de exploração e o campesinato protagonista central na luta de classe na busca da terra como condição de vida" (LIMA, 2012, p. 139). Sendo assim, de um lado está o agronegócio como produto da ação do capital, enquanto do outro aparece o campesinato evidenciando as territorialidades locais.

A intensificação da ação do capital no campo também foi responsável pela migração de milhares de pessoas que deixaram o campo em direção à cidade, haja vista que esse processo configurava-se como um obstáculo para aqueles que se dedicavam as atividades agropecuárias em pequena escala. Assim, "os estudos e as pesquisas que miram a estrutura territorial do Cerrado têm apontado uma síntese: o campo esvaziou-se de gente e se encheu de bois e grãos; a cidade encheu-se de gente e se tornou desigual" (CHAVEIRO; CALAÇA, 2012, p. 198).

De acordo com Porto Gonçalves (2004), os camponeses dos cerrados estão desapropriados por um modelo que não democratiza seus benefícios

[...] seja pela elevada magnitude de capital que exige para aceder a todo o pacote tecnológico; seja pelas enormes extensões de terras; seja, ainda, pela diminuição de preços agrícolas que provoca, impedindo que cheguem ao mercado aqueles que estão abaixo do nível de produtividade médio, sempre rebaixado pelas grandes empresas do agronegócio (PORTO GONÇALVES, 2004, p. 223). 
Tal situação revela que a expansão do capital no campo, apesar de proporcionar a diminuição dos valores dos produtos agrícolas, foi responsável pela ampliação da desigualdade existente entre a agricultura praticada em grande escala e a praticada em pequena escala. Assim, em decorrência de sua estrutura social injusta, essa expansão deixou de beneficiar grande parte da população (PORTO GONÇALVES, 2004).

Além das dificuldades já citadas para o desenvolvimento socioeconômico dos povos cerradeiros no campo, Matos e Pessoa (2009) apontam que o Estado pouco considerou a importância desses povos durante o processo de modernização das atividades agropecuárias no Cerrado, tendo em vista que "os incentivos por meio de financiamentos, programas e infra-estruturas eram voltados principalmente para os produtores sulistas que já possuíam tradição e experiência na agricultura moderna" (MATOS; PESSOA, 2009, p. 10).

Nesse contexto, podemos verificar que a territorialização do capital configurase como um obstáculo para a permanência no campo daqueles estão ligados às atividades agrícolas praticadas em pequena escala. Desse modo, as práticas, saberes e culturas camponesas perdem espaço, o que faz com que a migração para a cidade se torne compulsória. De acordo com Chaveiro e Calaça:

A força das commodities agrícolas comandada pelo agronegócio não apenas desarticula as práticas e as táticas de vida camponesas, mas cria níveis de desterritorialização total do sujeito. Sem lugar no campo não possui um lugar também nas cidades. Resulta disso uma proletarização que se estende espacialmente nos confins das periferias proletárias das metrópoles (CHAVEIRO; CALAÇA, 2012, p. 199).

Para Matos e Pessoa (2009), o processo de territorialização do capital e a consequente desterritorialização das pessoas, faz com que estas busquem novas alternativas, seja no campo ou na cidade, configurando um processo de reterritorialização.

\section{CONCLUSÃO}

A partir da leitura do material selecionado, constatamos que o campo brasileiro passou por mudanças significativas a partir da década de 1960, 
principalmente, em função do processo de territorialização do capital. Essa territorialização contou com forte apoio e incentivo do Governo Federal do Brasil e tinha como objetivo principal proporcionar a modernização da agricultura. Para o Estado brasileiro, a modernização da agricultura brasileira era necessária naquele momento, haja vista que o aumento da produção e da produtividade agrícola poderia colaborar para promover a internacionalização da economia brasileira.

No Cerrado, o processo de territorialização do capital se consolidou a partir da década de 1970. A partir desse período, o Cerrado brasileiro passou a receber uma série de investimentos financeiros do Governo Federal e de instituições privadas nacionais e internacionais, que tinham como objetivo inserir o bioma em questão nas demandas da economia internacional.

O processo de territorialização do capital no Cerrado proporcionou desdobramentos socioambientais significativos para o referido bioma, haja vista que a mesma territorialização do capital que proporcionou a modernização da agricultura e, por consequência, o aumento da produção e da produtividade, também proporcionou uma série de desdobramentos socioambientais negativos.

Do ponto de vista social, podemos apontar que a expansão do capital no campo foi responsável por expulsar milhares de famílias do campo, aumentar a concentração fundiária e de renda, desarticular comunidades rurais tradicionais, diminuir a importância dos saberes e das culturas locais e dificultar o desenvolvimento das atividades agrícolas praticadas em pequena escala. Já no que se refere aos desdobramentos ambientais, podemos apontar: desmatamento da vegetação nativa; poluição dos recursos hídricos, do solo e da vegetação em decorrência da utilização demasiada de agrotóxicos; e, diminuição da biodiversidade.

Analisando as vantagens e desvantagens proporcionadas pela territorialização do capital no Cerrado, podemos afirmar que as desvantagens são mais significativas que as vantagens, tendo em vista que os danos socioambientais gerados por esse processo provocaram uma profunda alteração estrutural na dinâmica do bioma em questão. Nesse contexto, podemos concluir que esse modelo de crescimento econômico, que é pautado na utilização e poluição demasiada dos 
recursos naturais e que não leva em conta a relevância das questões sociais, está proporcionando a degradação do Cerrado brasileiro.

\section{REFERÊNCIAS}

ALMEIDA, R. A. Territorialização complexo eucalipto-celulose-papel em Mato Grosso do Sul. Anais XXI Encontro Nacional de Geografia Agrária. Uberlândia, 2012. p. 1-19. Disponível em:

<http://www.lagea.ig.ufu.br/xx1enga/anais_enga_2012/eixos/1291_1.pdf>. Acesso em: 14 jan. 2014.

ANDRADE, Manuel Correia de. Agricultura e capitalismo. São Paulo: LECH, 1979.

CANUTO, A. Agronegócio: a modernização conservadora que gera exclusão pela produtividade. Revista NERA. Presidente Prudente, ano 7, n. 5, jul./dez. 2004, p. 1-12. Disponível em: <http://revista.fct.unesp.br/index.php/nera/article/viewFile/1466/1442>. Acesso em: 23 jan. 2014.

CHAVEIRO, E. F.; CALAÇA, M. Por uma abordagem territorial do Cerrado Goiano. In: SAQUET, M. A.; DANSERO, E.; CANDIOTTO, L. Z. P. (Org.). Geografia da e para a cooperação ao desenvolvimento territorial: experiências brasileiras e italianas. 1ed. São Paulo: Outras Expressões, 2012. v. 1, p. 191-206.

CALAÇA, M. Territorialização do capital: biotecnologia, biodiversidade e seus impactos no cerrado. Revista Ateliê Geográfico. Goiânia, v. 1, n. 9, fev/2010, p. 6-23. Disponível em: <http://www.revistas.ufg.br/index.php/atelie/article/view/16680 >. Acesso em: 10 jul. 2013.

FIDELIS, A. C.; LIMA, J. D. Impactos ambientais da silvicultura no bioma cerrado. Anais V Simpósio Nacional de Geografia Agrária. Niterói, 2009. p. 1-11. Disponível em: <http://www.uff.br/vsinga/trabalhos/Trabalhos\%20Completos/Alex\%20Camargo\%20Fidelis.pdf >. Acesso em: 15 jul. 2013.

GRAZIANO DA SILVA, J. A modernização dolorosa: estrutura agrária, fronteira agrícola e trabalhadores rurais no Brasil. Rio de Janeiro: Zahar, 1982.

KUDLAVICZ, Mieceslau. Dinâmica agrária e a territorialização do complexo celulose/papel na microrregião de Três Lagoas/MS. 2011. 177 f. Dissertação (Mestrado em Geografia). Universidade Federal de Mato Grosso do Sul, Três Lagoas, 2011.

LIMA, J. R. Contradições na produção do espaço rural brasileiro: modernização do campo, espacialização da pobreza e resistência. Revista GeoNordeste. Ano XXIII, n. 1, p. 136-156, 2012. Disponível em:

<http://200.17.141.110/pos/geografia/geonordeste/index.php/GeoNordeste/article/view/274>. Acesso em: 12 jul. 2013.

MARTINS, José de Souza. Capitalismo e tradicionalismo: estudos sobre as contradições da sociedade agrária no Brasil. São Paulo: Pioneira, 1975.

MATOS, P. F.; PESSÔA, V. L. S. Territorialização da agricultura moderna na região da estrada de ferro (Goiás) e as modificações no espaço agrário. XIX Encontro Nacional de Geografia Agrária. São Paulo, 2009, p. 1-18.Disponível em:

<http://www.geografia.fflch.usp.br/inferior/laboratorios/agraria/Anais\%20XIXENGA/artigos/Matos_PF.p df>. Acesso em: 15 jul. 2013. 
OLIVEIRA, Ariovaldo Umbelino de. A agricultura camponesa no Brasil. 2 ed. São Paulo: Contexto, 1996.

PORTO GONÇALVES, Carlos Walter. Geografia da riqueza, fome e meio ambiente: pequena contribuição crítica ao atual modelo agrário/agrícola de uso dos recursos naturais. In: Oliveira, Ariovaldo Umbelino de; Marques, Marta Inez Medeiros (Orgs.). O campo no século XXI: território de vida, de luta e de construção da justiça social. São Paulo: Editora Casa Amarela e Editora Paz e Terra, 2004. p. 207-253.

SANTOS, R. R. A territorialização do capital e as relações camponesas de produção. Revista Campo-Território. Uberlândia, v. 2, n. 3, fev/2007, p. 40-54.

Disponível em: <http://www.seer.ufu.br/index.php/campoterritorio/article/view/11800/8415>. Acesso em: 17 jul. 2013. 